\title{
DesAmadas
}

Nana Moraes*

Desde o ano de 2007, comecei a desenvolver a trilogia de livros DesAmadas, onde busco desvelar histórias de mulheres discriminadas, estigmatizadas, que sobrevivem ao preconceito, à intolerância, desprezadas na sociedade perversa.

O primeiro livro, Andorinhas, conta as histórias de cinco prostitutas que trabalham na Rodovia Presidente Dutra: Doroth, Gerenilza, Simone, Roseli e Bétissa. Serei sempre grata por me permitirem entrar em suas vidas. Em nossas conversas, entre muitos casos, elas sempre mencionavam o fato de que a prostituição não é crime. Embora, nem por tanto livrem-se de perpétuo julgamento. Talvez por isso, logo que lancei Andorinhas, comecei a me inquietar com outras mulheres. As mulheres encarceradas.

Então realizei o trabalho Ausência, onde trago as relações de mães presidiárias com suas filhas e filhos. Este segundo trabalho começou pela a exposição, e está fazendo uma bela trajetória até aqui: Centro Cultural Correios, FotoRio 2017; Casa da Cultura, Paraty em Foco 2017; e Fiocruz, em 2018/2019. Na Fiocruz participou das comemorações dos 70 anos da Declaração dos Direitos Humanos, e a exposição teve a honra de ser aberta por Michelle Bachelet. E, em 2019, recebi por Ausência, a Medalha Jorge Careli de Direitos Humanos da ASFOC, dos servidores da Fiocruz.

Agora, estou escrevendo o livro que fará parte da trilogia: Ausência, correspondência fotográfica. O livro é ao mesmo tempo um desdobramento da exposição e, uma outra escuta para as mesmas histórias que constroem este trabalho. Ambos são fruto do projeto Travessia, que realizei no presídio Nelson Hungria no Complexo de Gericinó, onde propus estabelecer uma correspondência fotográfica entre as mães presas e suas filhas e filhos.

\footnotetext{
* Fotógrafa, nasceu em 1963 no Rio de Janeiro. Formada em jornalismo pela Pontifícia Universidade Católica de São Paulo, colabora há 30 anos para os mercados editorial, cultural e publicitário. Hoje, também, está a frente do Retrato Espaço Cultural. Foi seis vezes vencedora do Prêmio Abril de Jornalismo - a última em 2010 - e premiada pela Associação Brasileira de Pro-paganda como "Destaque Profissional/Fotografia", em 2007 e 2011. Desde 2018 integra a equipe de coordenação do FotoRio. E-mail: nanamoraes@nanamoraes.fot.br.
}

DOI: $10.12957 /$ rep.2021.56066

A Revista Em Pauta: Teoria Social e Realidade Contemporânea está licenciada com uma Licença Creative Commons Atribuição 4.0 Internacional. 


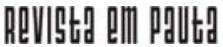

\} DESAMADAS - MORAES, N. \}

DOI: $10.12957 /$ rep.2021.56066

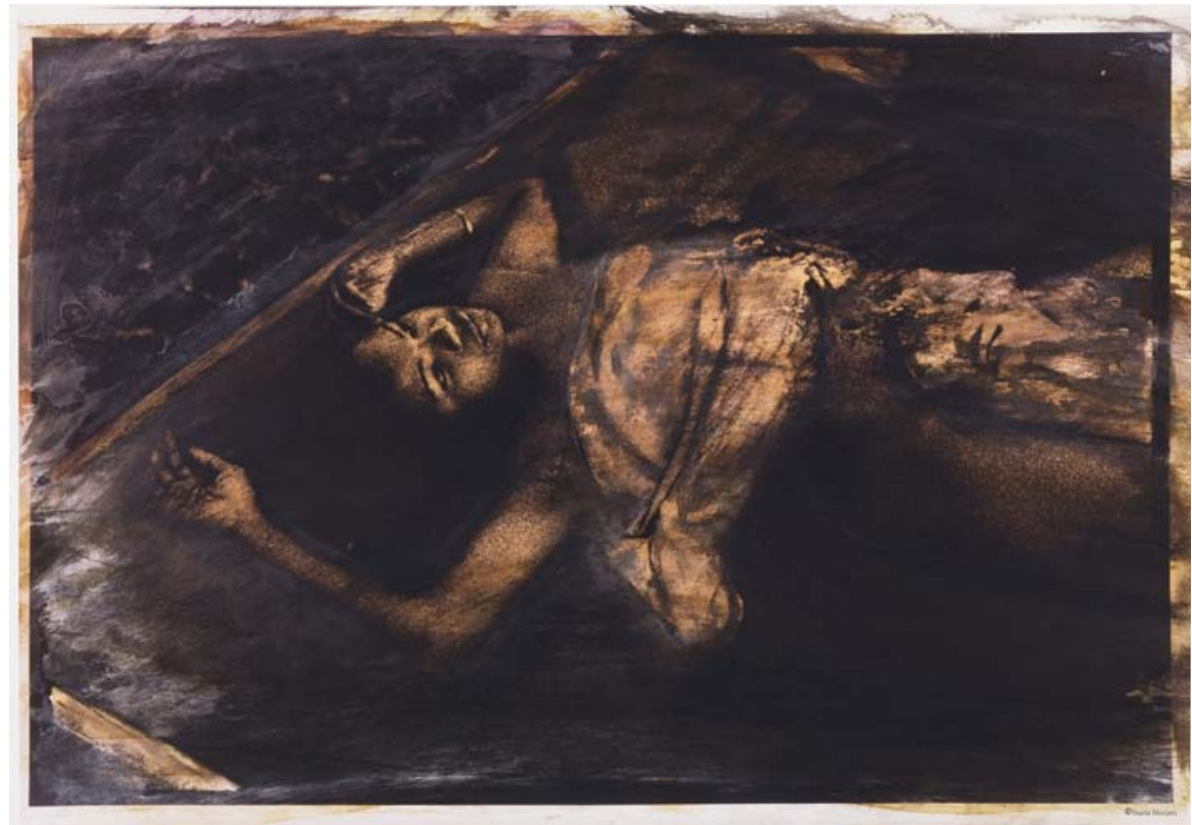

Betissa 1 


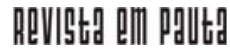

\} DESAMADAS - MORAES, N. \}

DOI: $10.12957 /$ rep.2021.56066

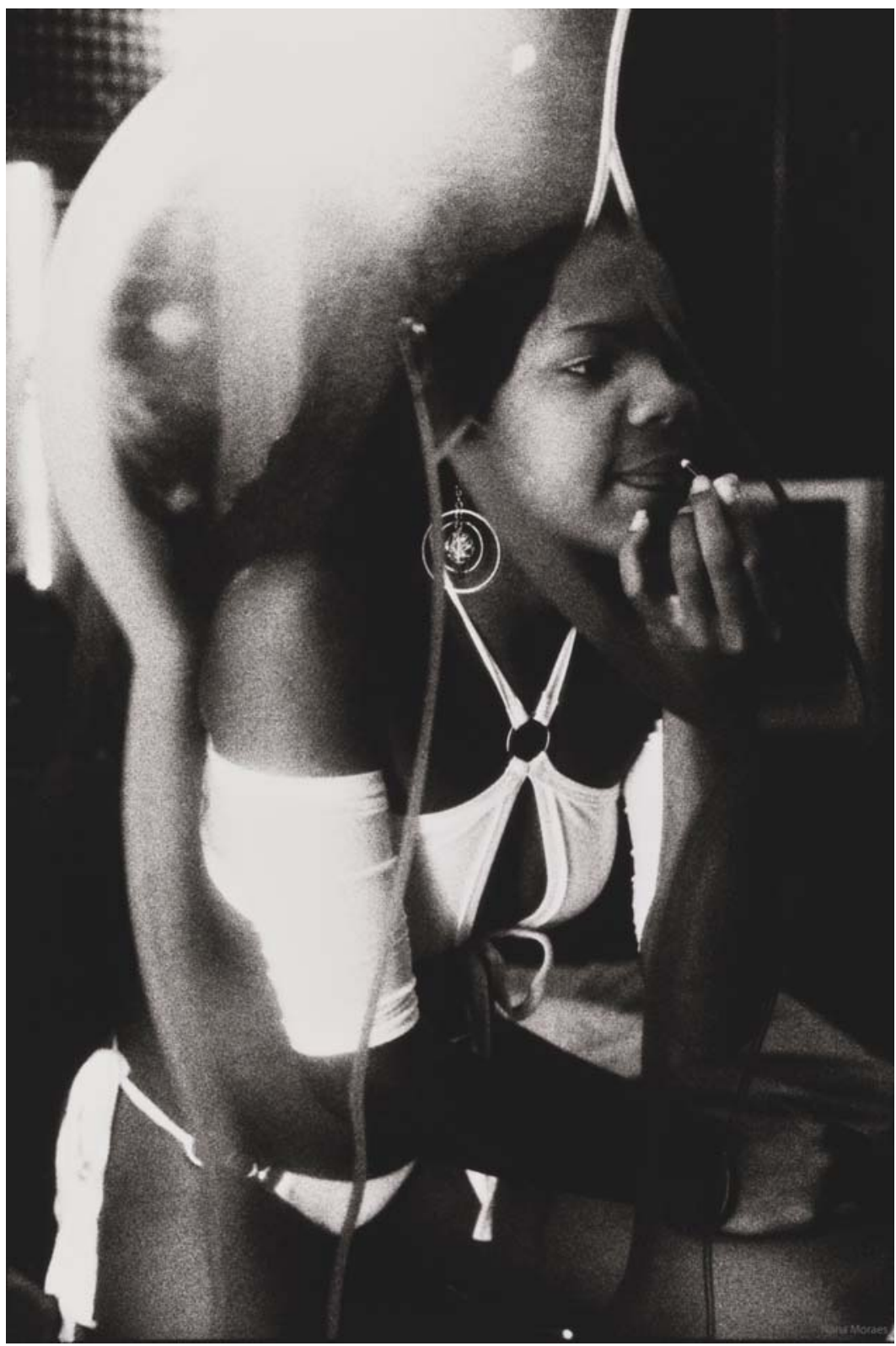

Betissa 2 


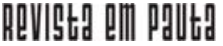

\} DESAMADAS - MORAES, N. \}

DOI: $10.12957 /$ rep.2021.56066

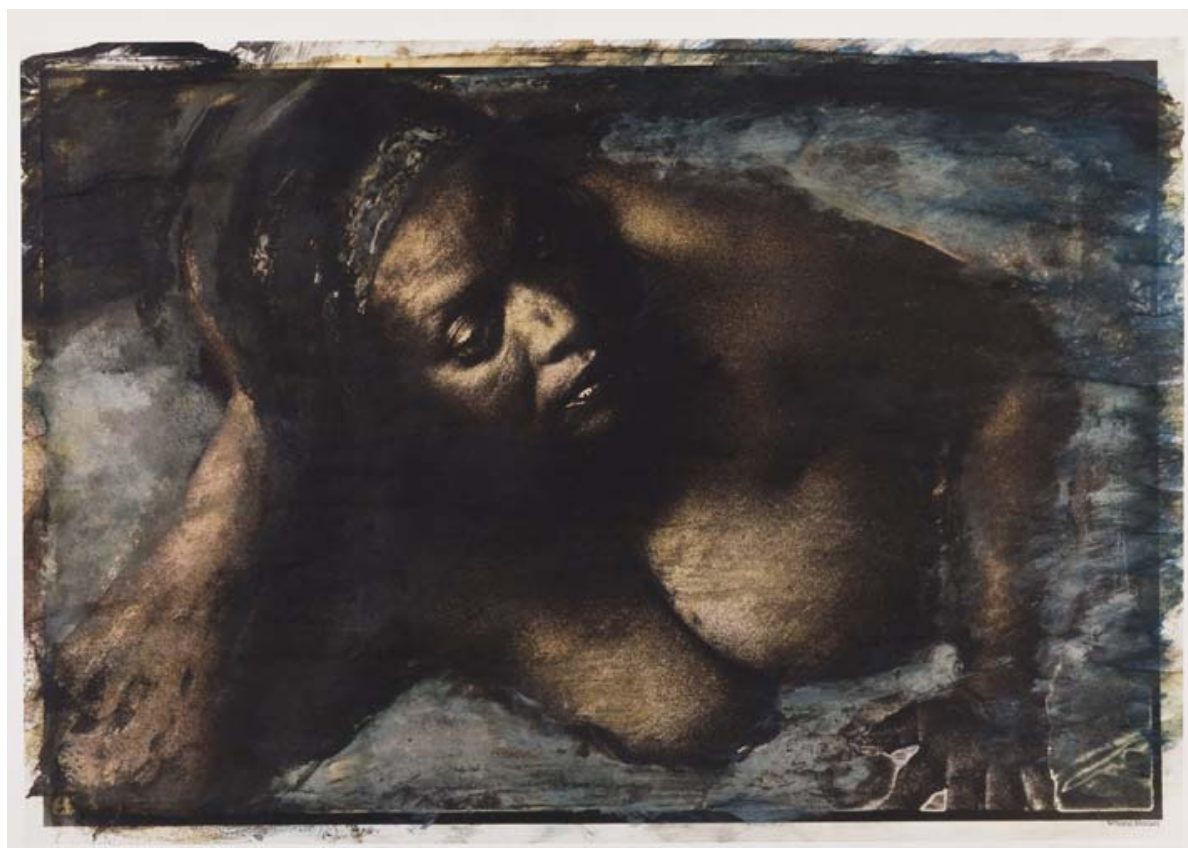

Doroth 1

EM PAUTA, Rio de Janeiro - $1^{\circ}$ Semestre de 2021 - n. 47, v. 19, p. 280 - 300 


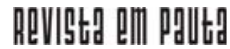

] DESAMADAS - MORAES, N.

DOI: $10.12957 /$ rep.2021.56066

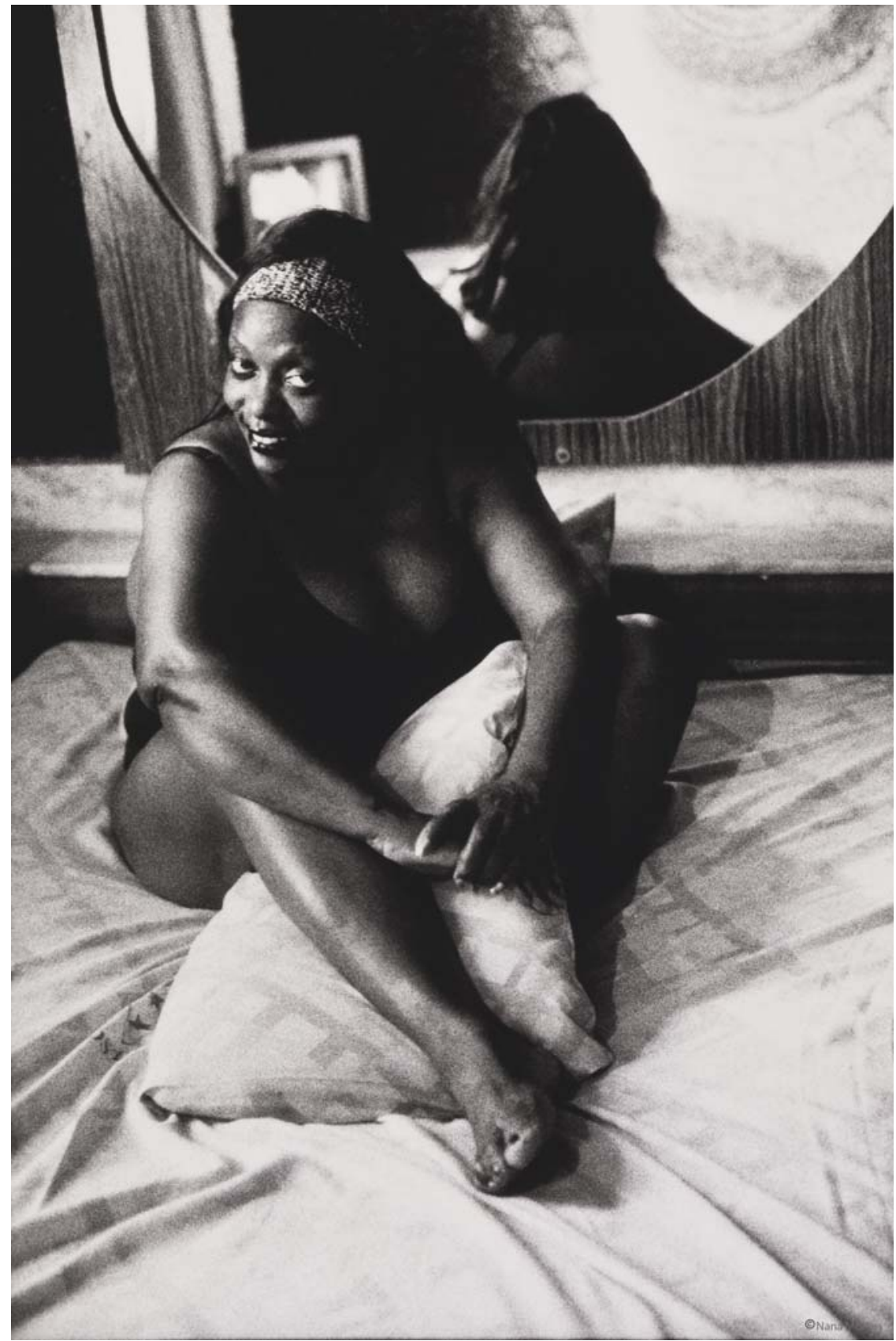

Doroth 2

EM PAUTA, Rio de Janeiro - $1^{\circ}$ Semestre de 2021 - n. 47, v. 19, p. 280 - 300 


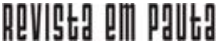

\} DESAMADAS - MORAES, N. \}

DOI: $10.12957 /$ rep.2021.56066

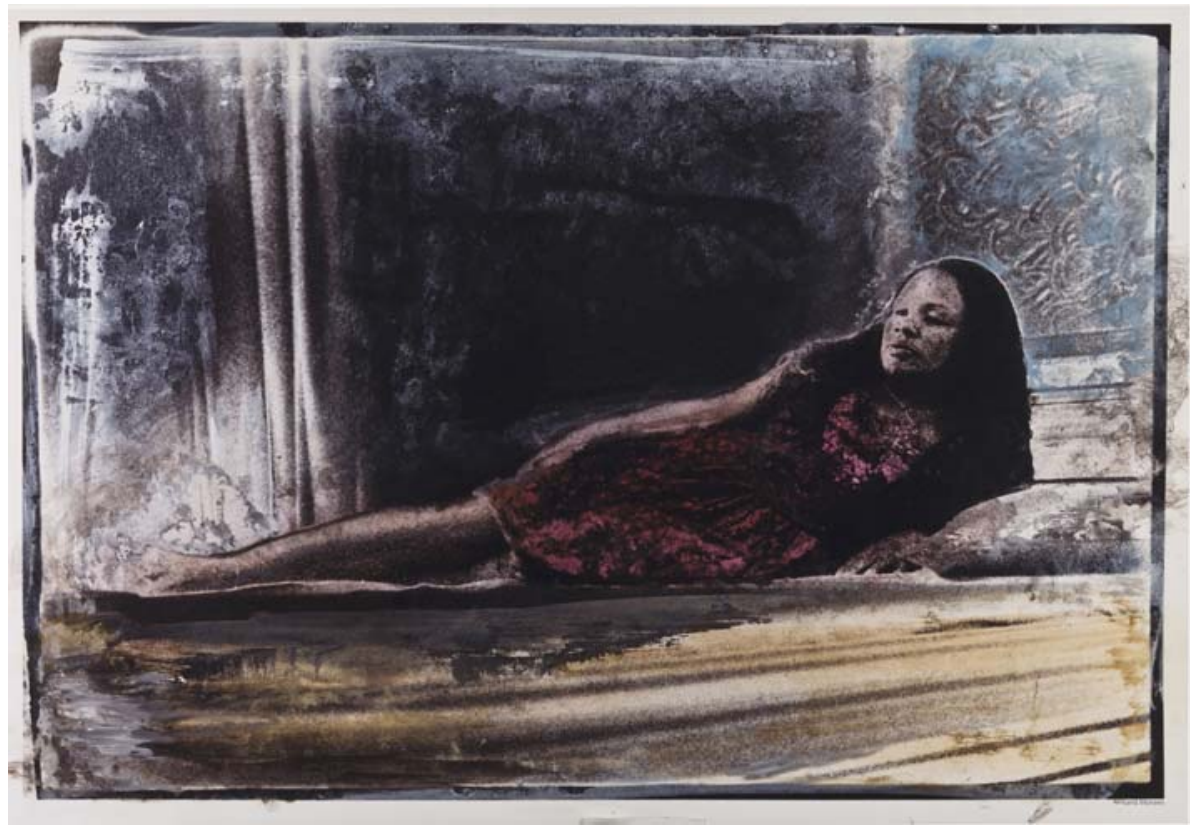

\section{Gerenilza 1}




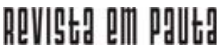

\} DESAMADAS - MORAES, N.

DOI: 10.12957/rep.2021.56066

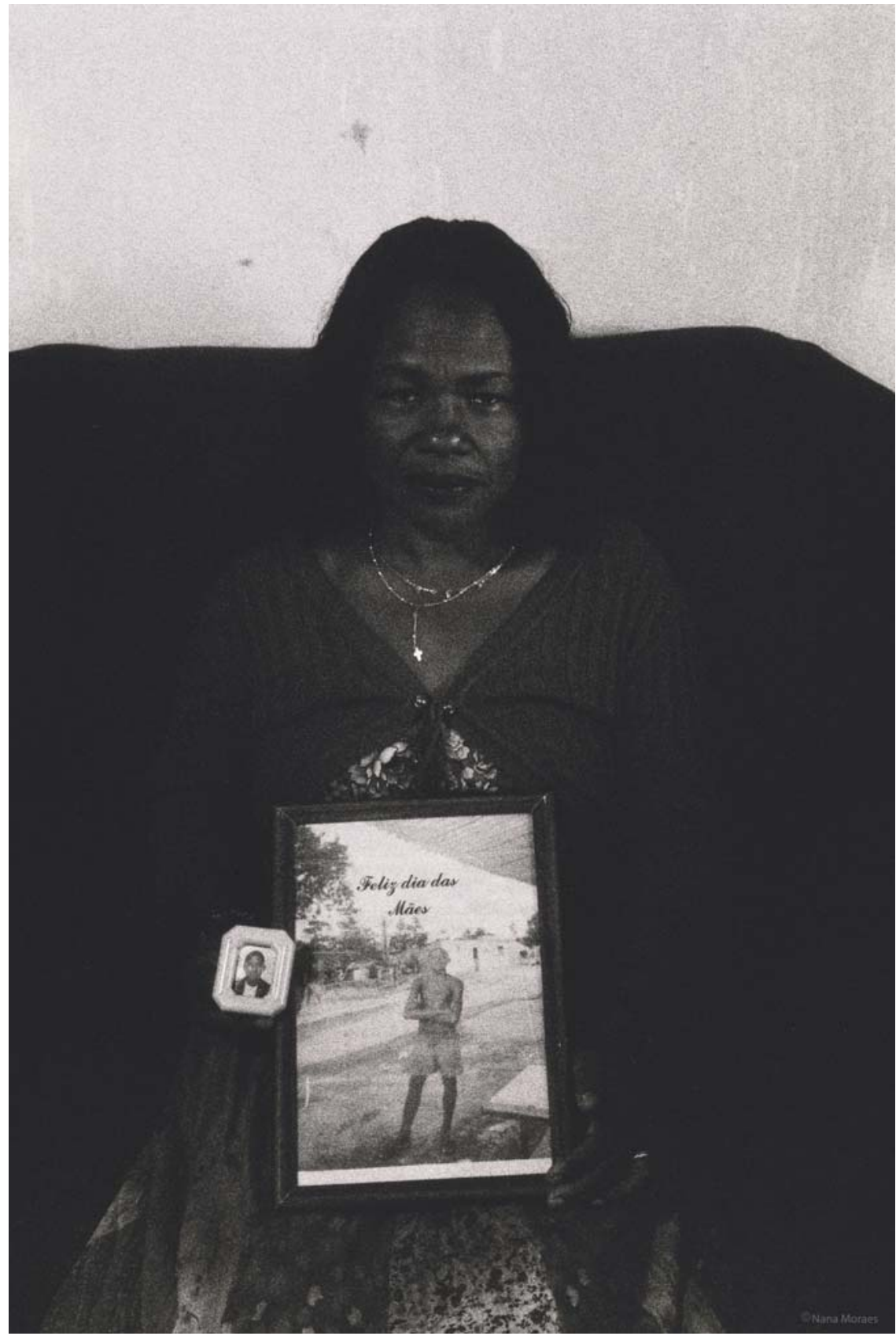

Gerenilza 2 


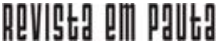

\} DESAMADAS - MORAES, N. \}

DOI: $10.12957 /$ rep.2021.56066

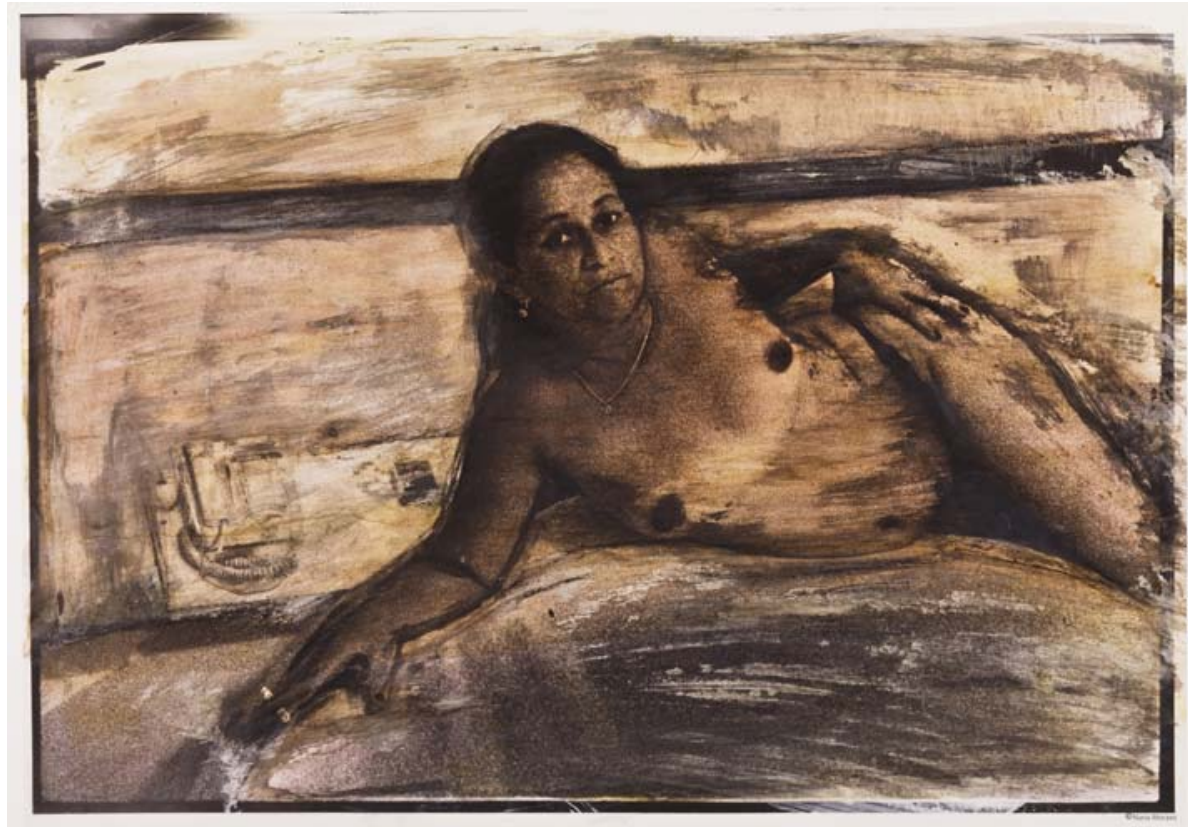

Roseli 1 


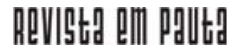

] DESAMADAS - MORAES, N.

DOI: $10.12957 /$ rep.2021.56066

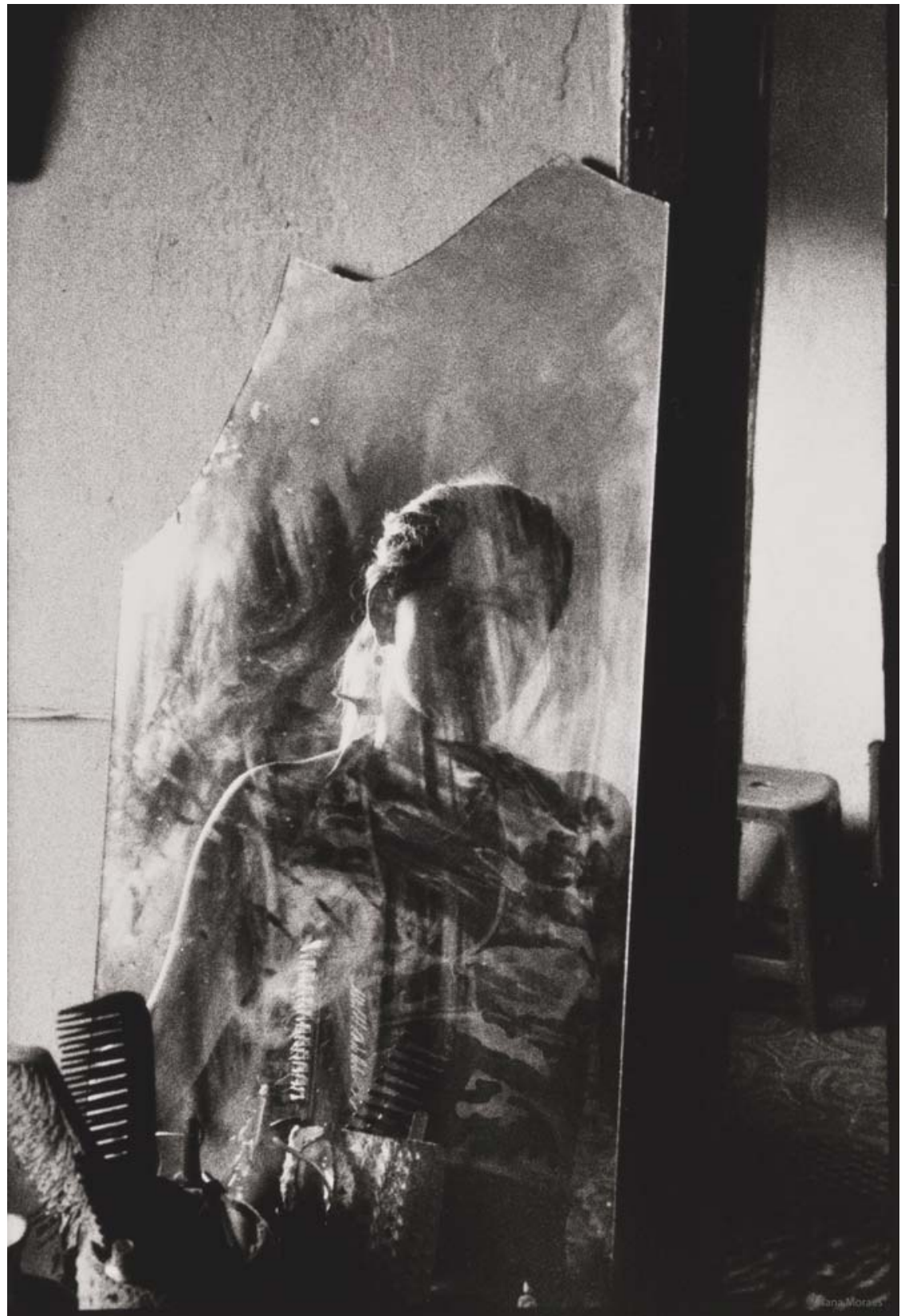

Roseli 2

EM PAUTA, Rio de Janeiro - $1^{\circ}$ Semestre de 2021 - n. 47, v. 19, p. 280 - 300 


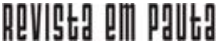

\} DESAMADAS - MORAES, N. \}

DOI: $10.12957 /$ rep.2021.56066

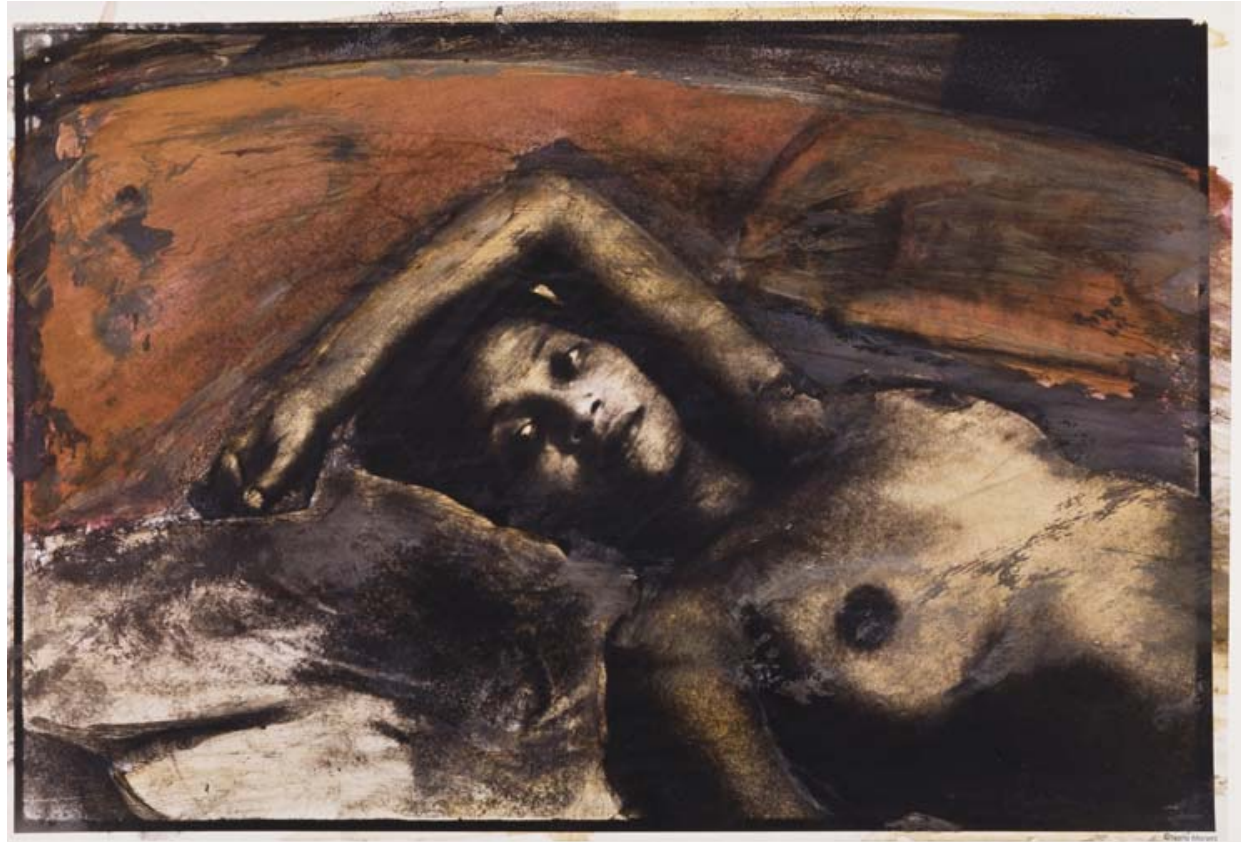

Simone 1

EM PAUTA, Rio de Janeiro - $1^{\circ}$ Semestre de 2021 - n. 47, v. 19, p. 280 - 300 


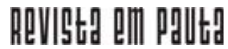

\} DESAMADAS - MORAES, N.

DOI: 10.12957/rep.2021.56066

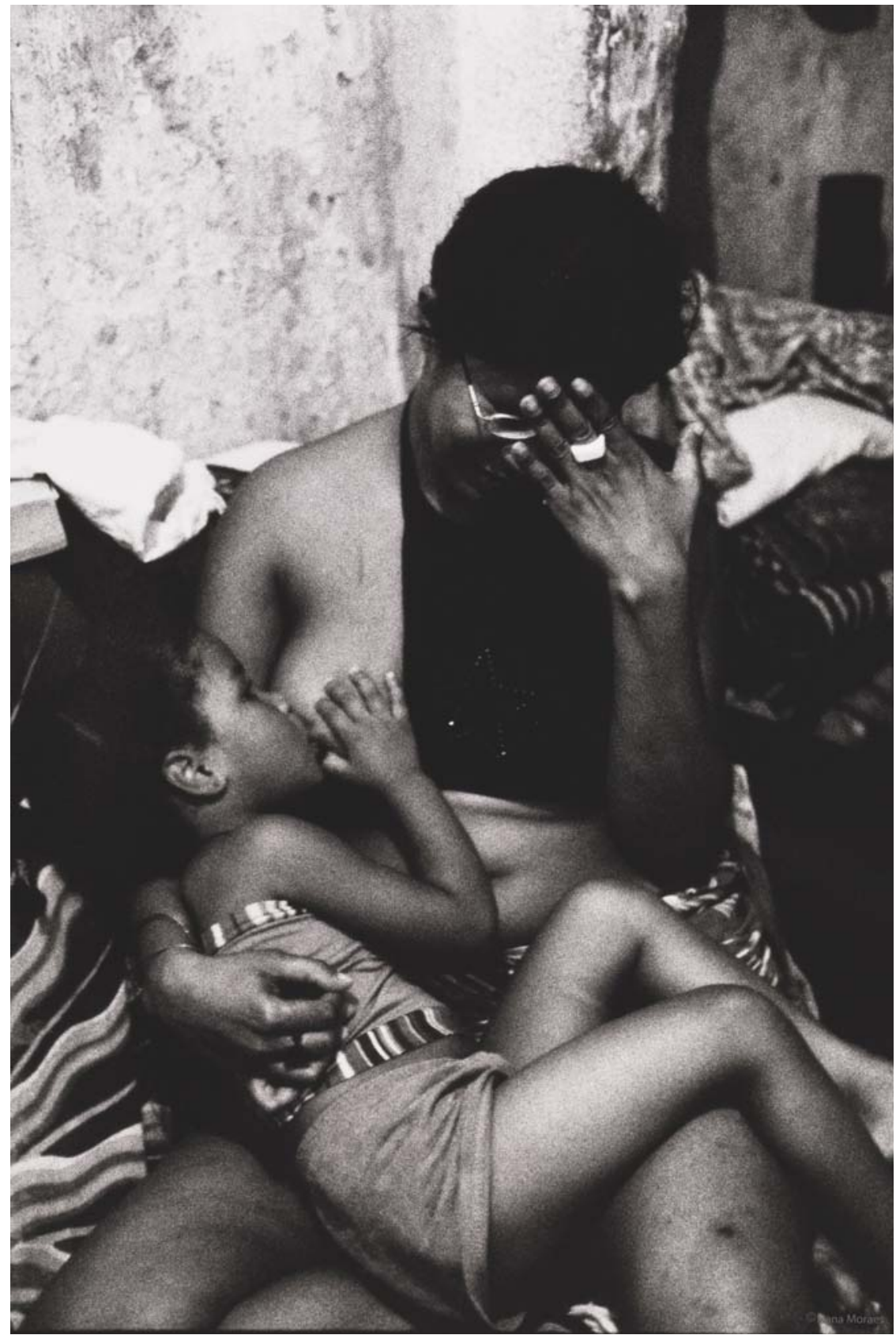

Simone 2 


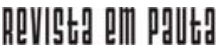

\} DESAMADAS - MORAES, N.\}

DOI: $10.12957 /$ rep.2021.56066

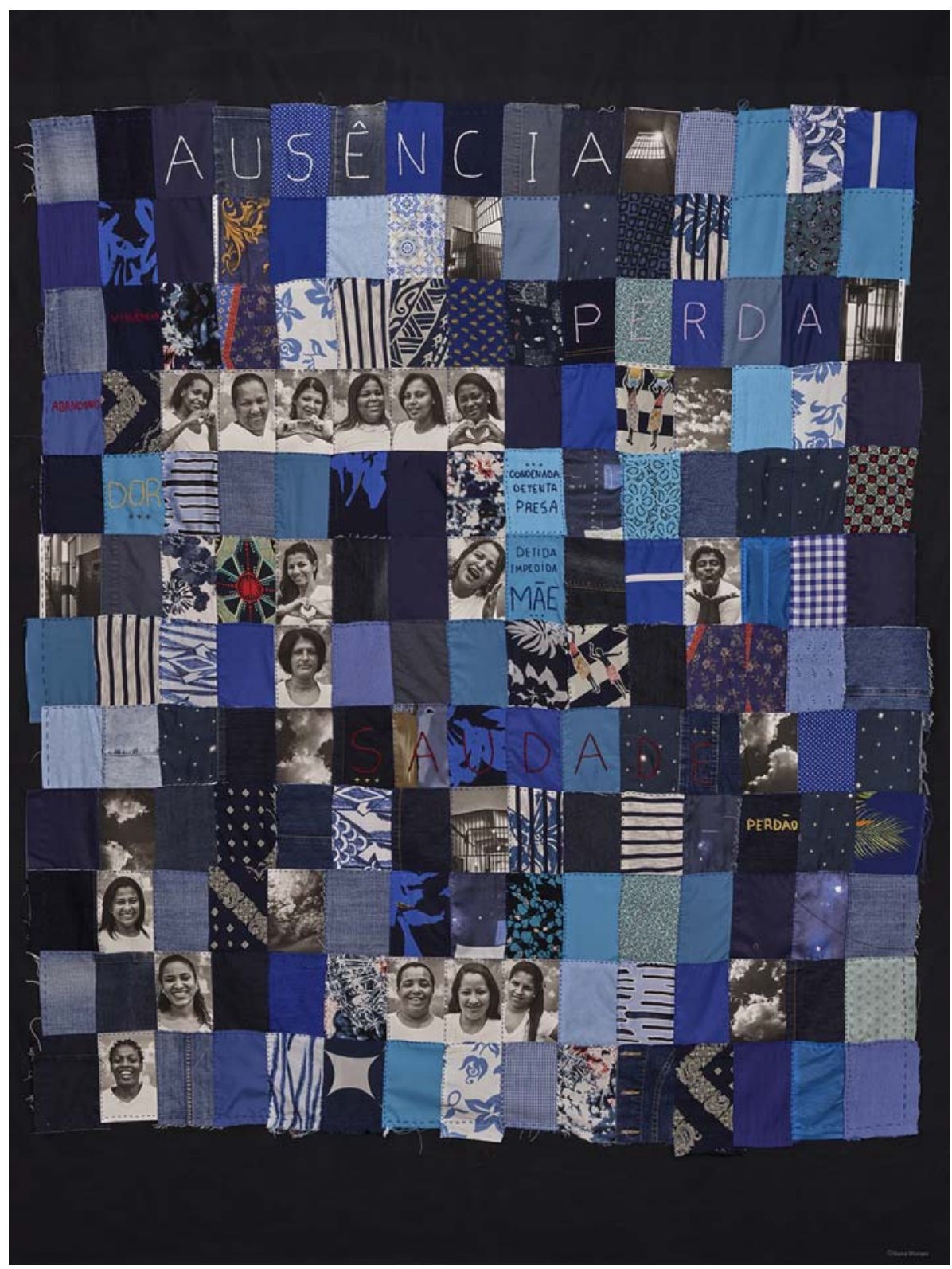

Ausência exposição 1 


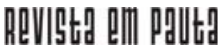

\} DESAMADAS - MORAES, N. \}

DOI: 10.12957/rep.2021.56066

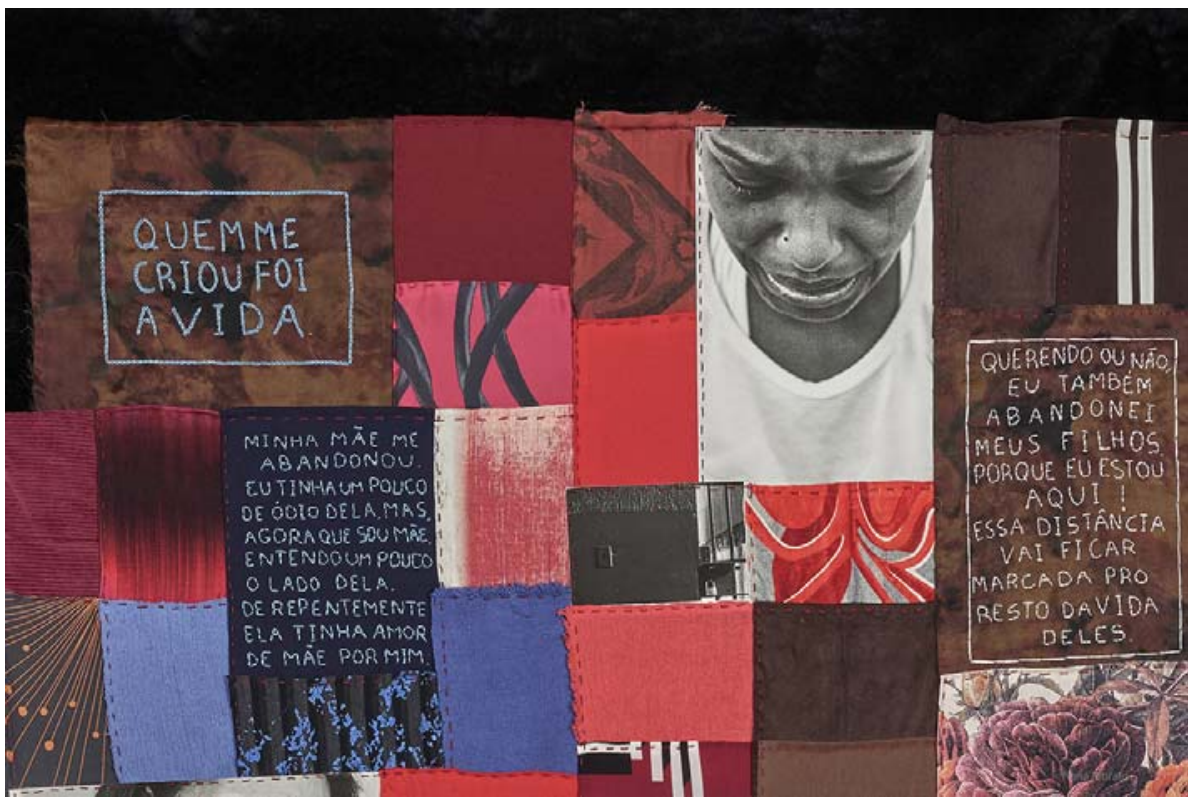

Ausência exposição 2 


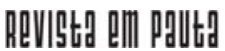

\} DESAMADAS - MORAES, N.\}

DOI: $10.12957 /$ rep.2021.56066

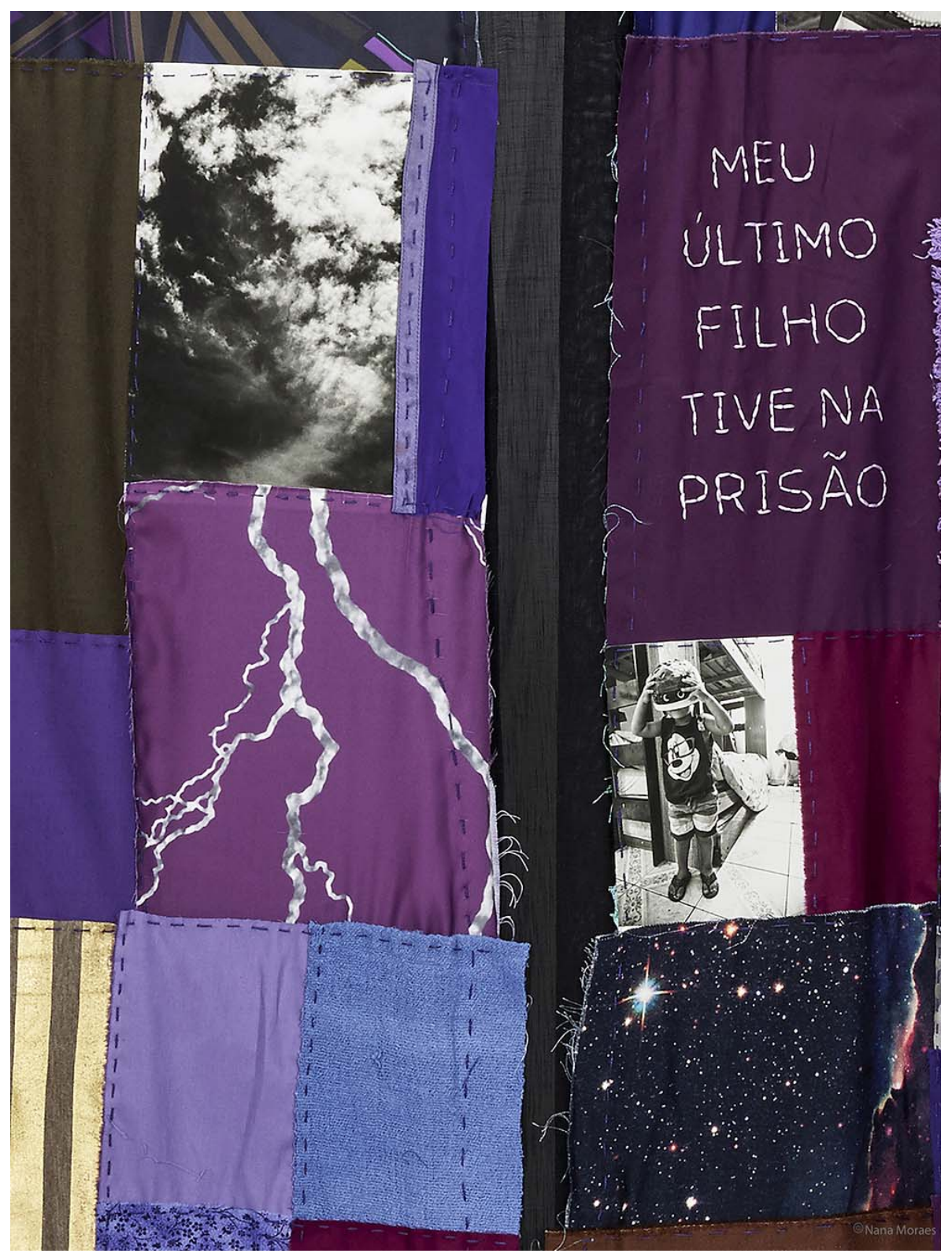

Ausência exposição 3 


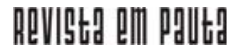

| DESAMADAS - MORAES, N.

DOI: $10.12957 /$ rep.2021.56066

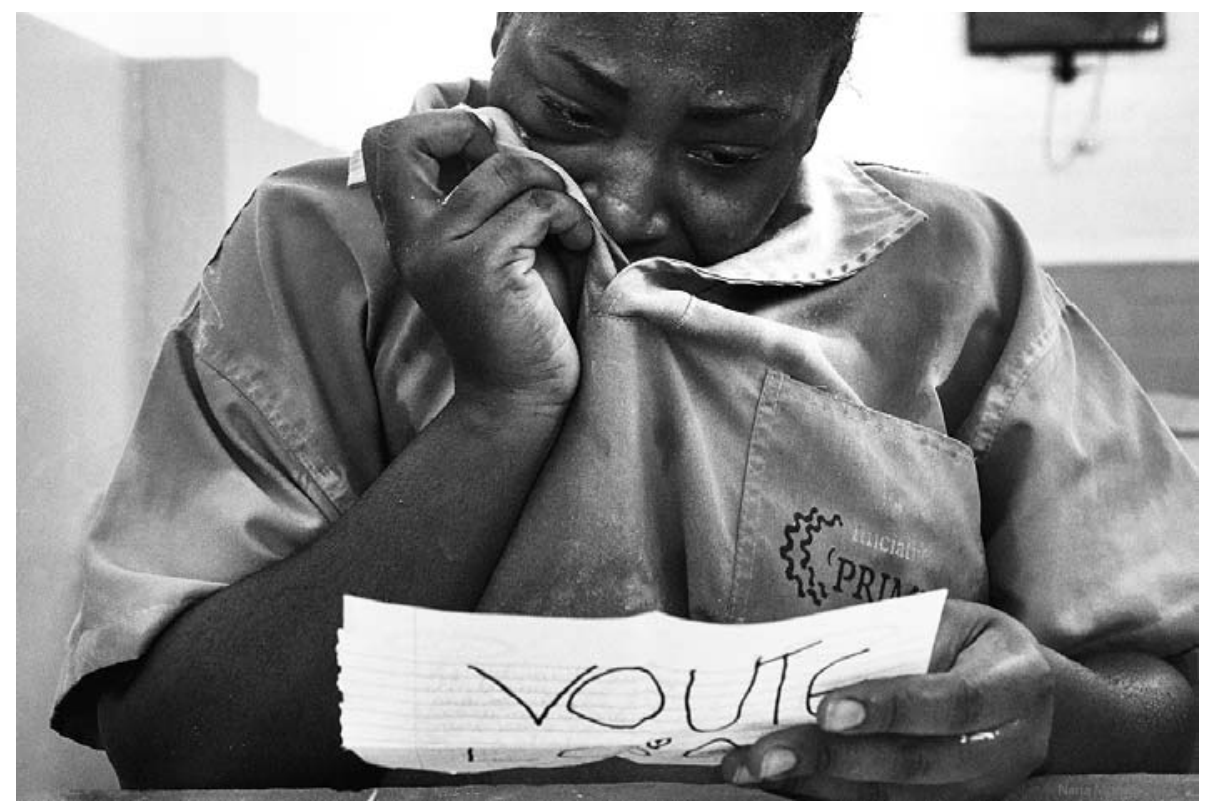

Ausência exposição 4 


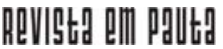

\} DESAMADAS - MORAES, N.\}

DOI: $10.12957 /$ rep.2021.56066

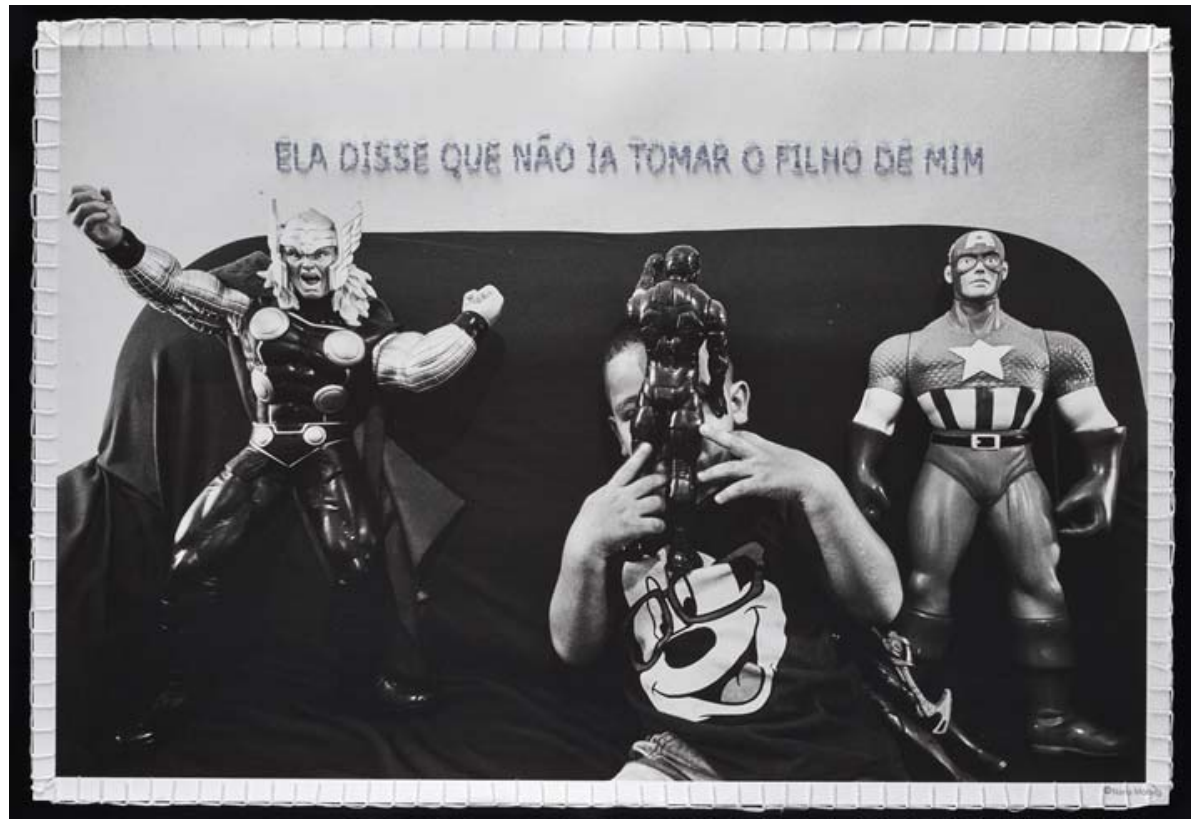

Ausência exposição 5 


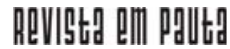

\} DESAMADAS - MORAES, N. \}

DOI: 10.12957/rep.2021.56066

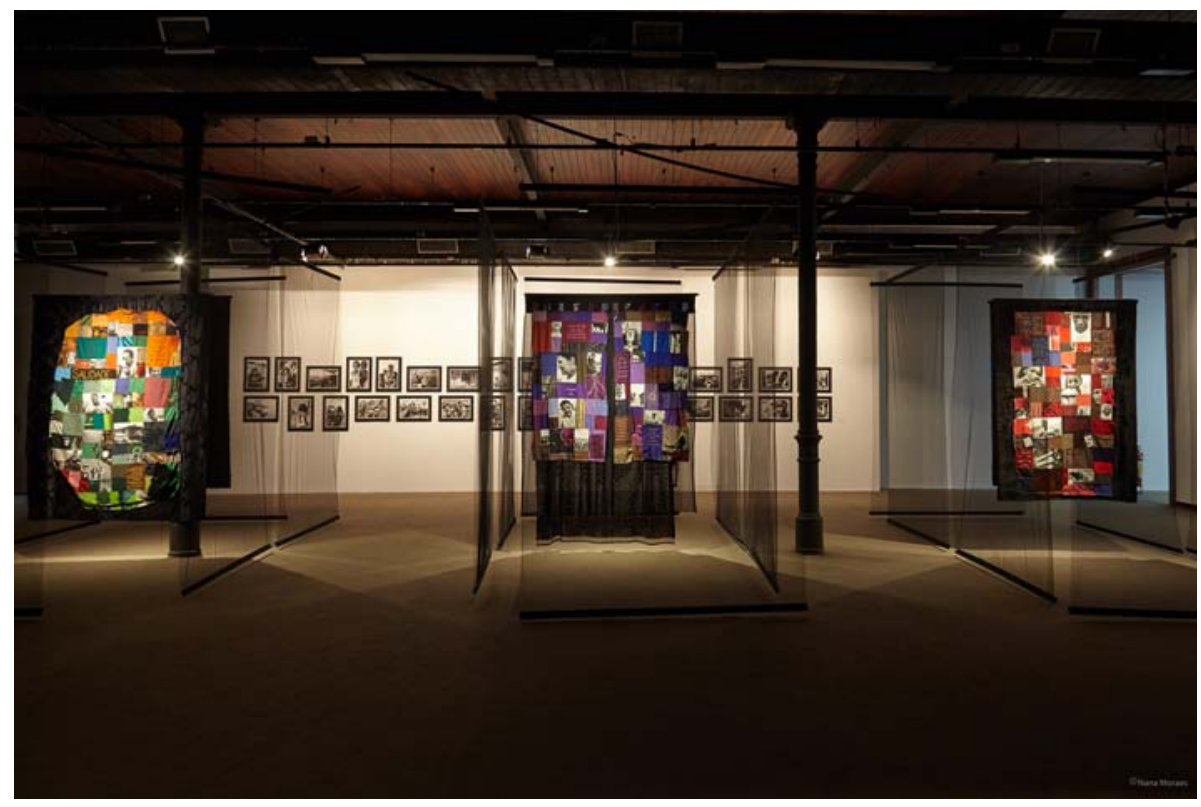

Ausência exposição 6 


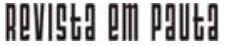

\} DESAMADAS - MORAES, N. \}

DOI: $10.12957 /$ rep.2021.56066
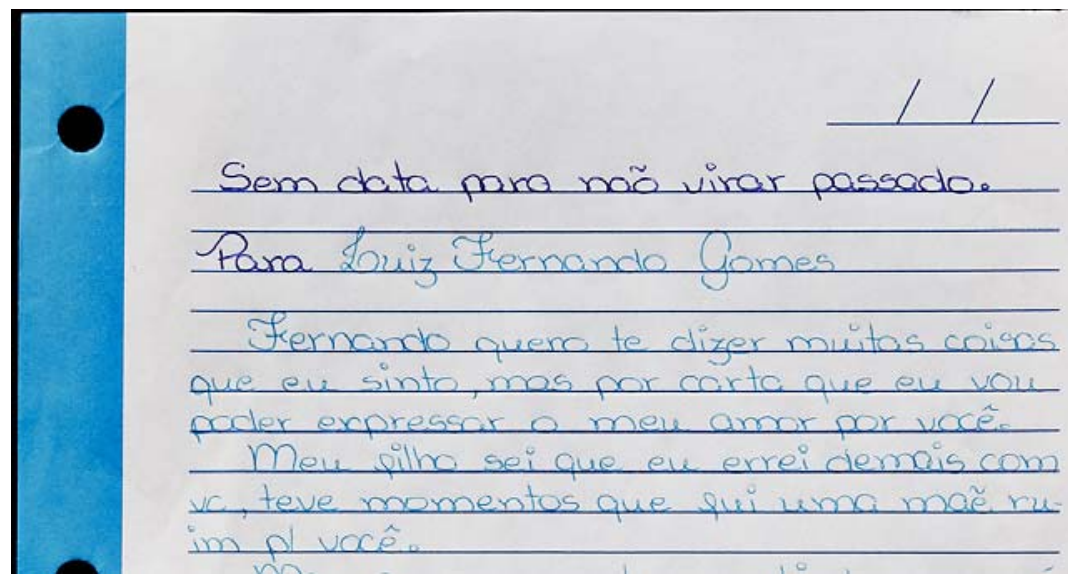

Ausência exposição 7 


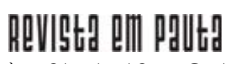

\} DESAMADAS - MORAES, N. \}
DOI: $10.12957 /$ rep.2021.56066

So te peco uma chance de te char nos olhos e dizers

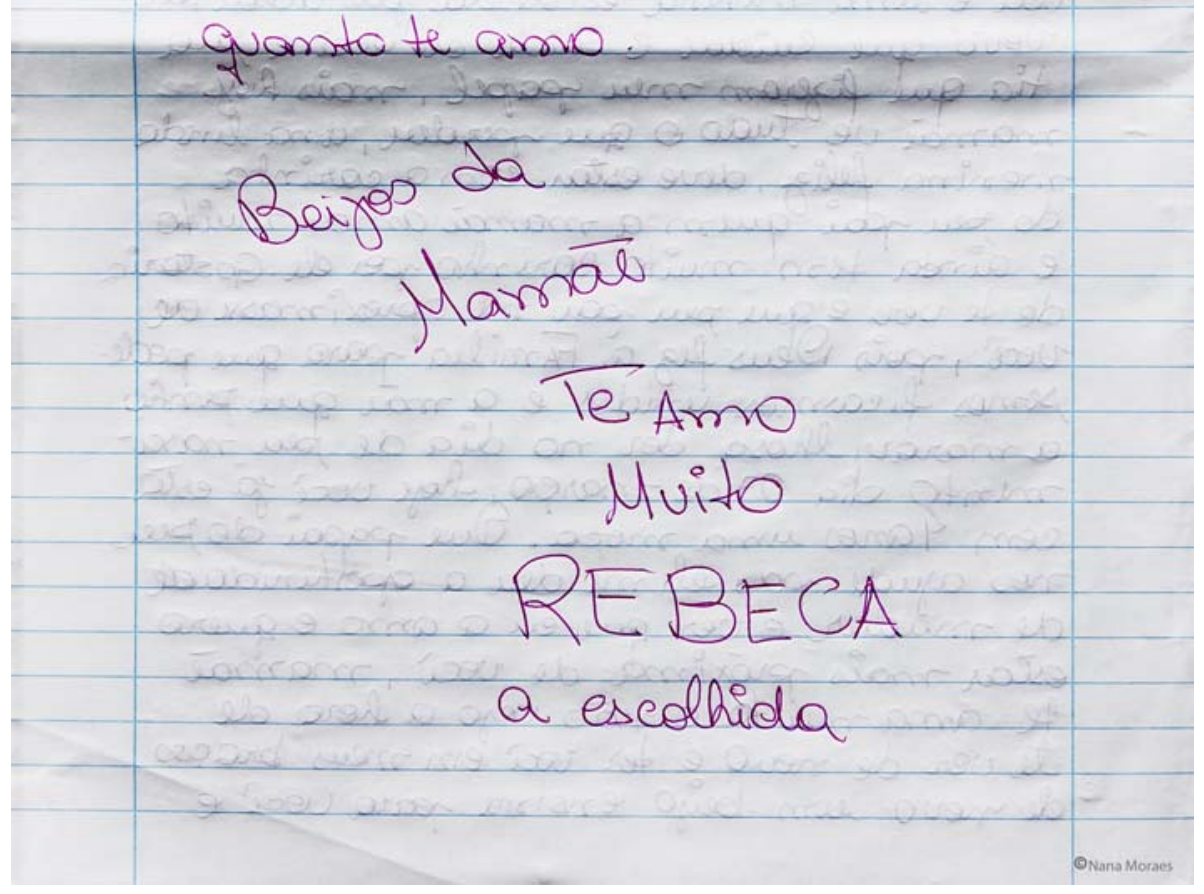

Ausência exposição 8

EM PAUTA, Rio de Janeiro - $1^{\circ}$ Semestre de 2021 - n. 47, v. 19, p. 280 - 300

298

Revista da Faculdade de Serviço Social da Universidade do Estado do Rio de Janeiro 


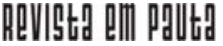

\} DESAMADAS - MORAES, N.\}

DOI: $10.12957 /$ rep.2021.56066

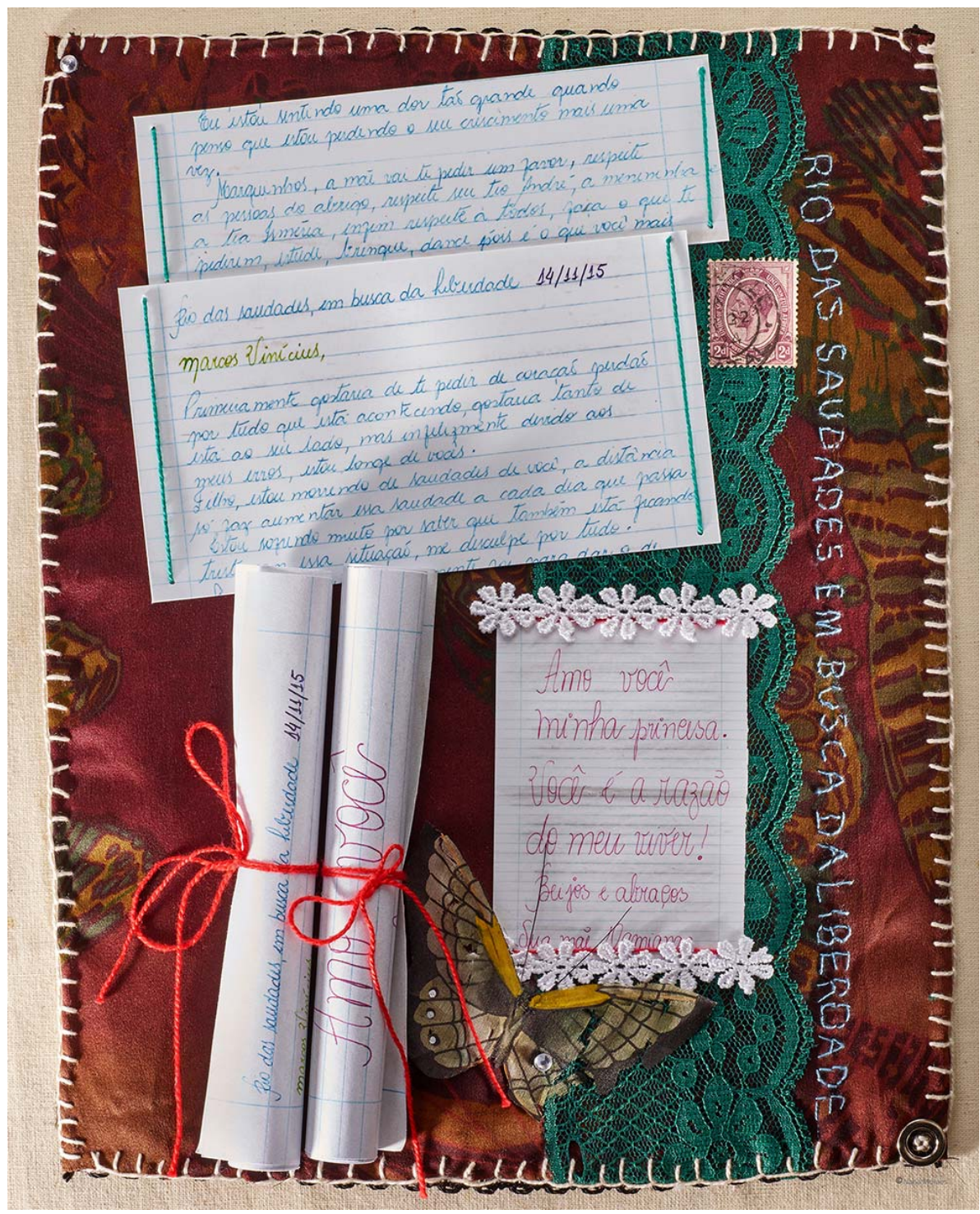

Ausência livro 1 


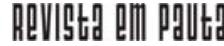

\} DESAMADAS - MORAES, N. \}

DOI: $10.12957 /$ rep.2021.56066

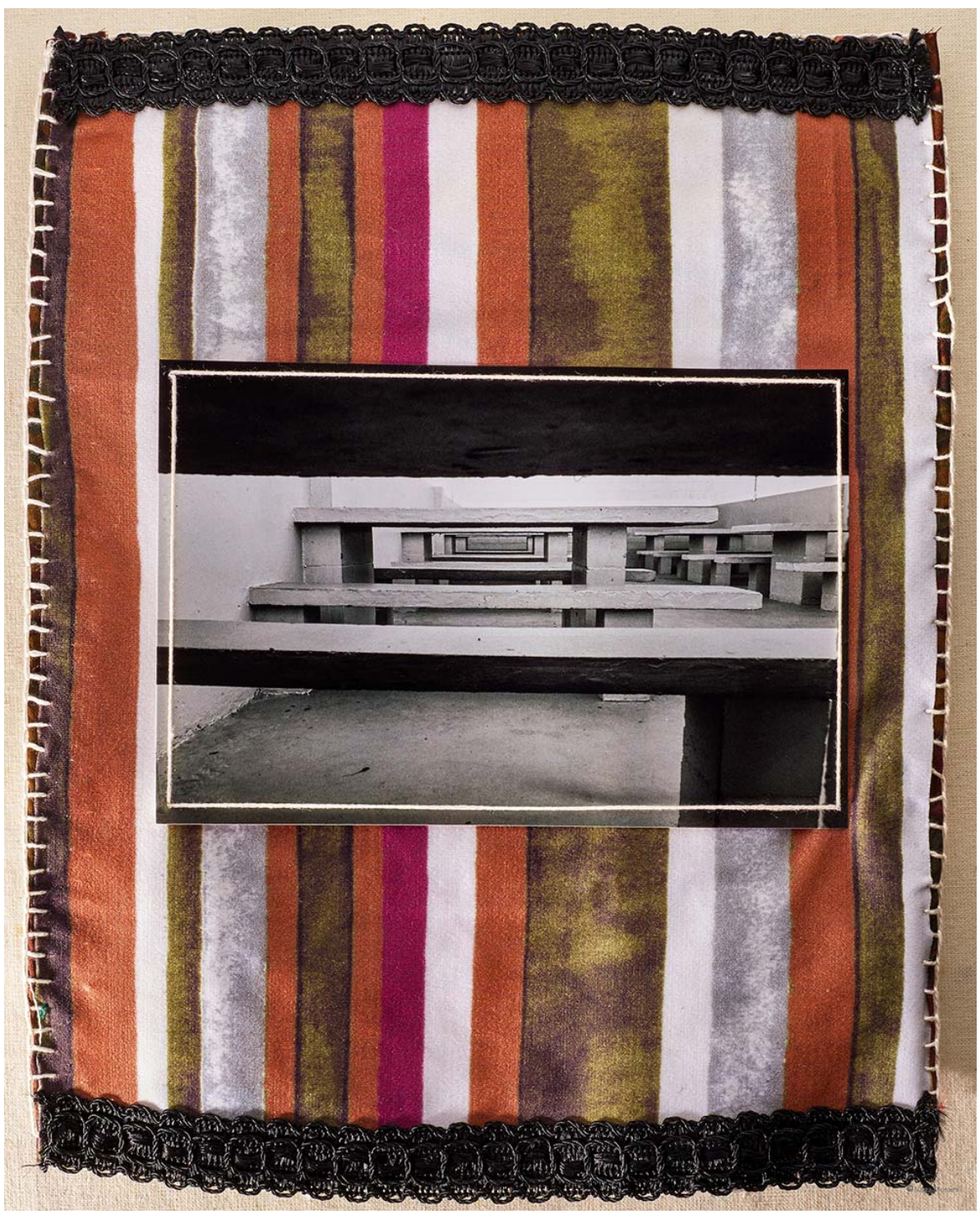

Ausência livro 2 